\section{FEATURE}

Gareth Clancy

\section{office for National Statistics}

\section{SUMMARY}

This article briefly considers a few of the changes in the labour market in the last 20 years and how these adjustments relate to the economy in the UK. It acknowledges that, during 2008, the timing of movements in output indicators and labour market statistics differed. To explore this, the economic background to 2008 is discussed, by presenting aggregate economic indicators for a selection of international trade partners and looking at other statistics produced by the Office for National Statistics. Finally, the developments in commodity prices and government policy over the last year are recognised.

\title{
The labour market and the economy 20 years reviewed
}

The labour market plays an important part in the economy, accounting for over half of the UK's national income. In the three months to June 2008, the share of national income related to the compensation of employees (wages, salaries and employers' social contributions) comprised around 52 per cent of national income (measured as compensation of employees divided by Gross National Income at market prices). Historically, the compensation of employees has accounted for a larger share of national income; nonetheless, it still remains imperative to closely analyse the labour market for macroeconomic purposes.

\section{Labour market position in the economy}

The labour market influences aggregate demand through consumption and investment, and is a key component of aggregate supply. As a factor of production in aggregate supply, the levels of employment and jobs in the UK economy represent the inputs required by firms to provide goods and services.

The relationship between macroeconomic indicators and the labour market is complex because of its influence on both supply and demand. However, over the past decade, the positive growth in Gross Domestic Product (GDP) has been accompanied by increasing employment levels. These increases have been made possible by a steady upward trend in labour demand (driven by employers), and just as significantly changes in the labour supply (which can result from population changes, labour market policies and participation rates). ${ }^{1}$

One of the more recent significant changes in labour supply has been as a result of international migration. Statistics released by the Office for National Statistics (ONS) in August 2008 showed that the population increased by almost 3 per cent between mid-2001 and mid2007. ${ }^{2}$ Net inward migration to the UK played an important role in this increase, accounting for 52 per cent of the increase in the 12 months to mid-2007. From an economic growth perspective, an increasing population is important because of the impact on the potential labour supply. An indication of how this has changed is given by the growth in National Insurance number applications from adult overseas nationals, published by the Department for Work and Pensions (DWP), which doubled between the financial years 2002/03 and 2007/08. ${ }^{3}$

In addition to the net inflow of overseas nationals, the labour supply has been increased by the continued rise in labour market participation by females. In the three months to September 1980, the female employment rate stood at 45.1 per cent. In the same periods in 1990 and 2008, it was 50.4 and 53.8 per cent, respectively. Offsetting this, male participation has fallen since 1980, and the average hours worked by individuals have been on a downward trend since 1990.

The relationship between levels of demand and supply within the labour market is important because of two 
alternative scenarios: labour market tightness, arising when demand is not sufficiently met by supply; and labour market slackness, which is when supply exceeds demand. The first scenario can lead to rising earnings growth, while the second can cause a slowdown or decline in earnings growth.

Rapid earnings growth and the consequent upward pressure on overall labour costs is one key mechanism through which inflationary pressure may be transmitted from the labour market to consumer prices (another being commodity prices). The increasing labour supply has influenced earnings in certain sectors of the labour market reducing the size of 'costpush' pressures.

Nominal earnings growth has been less volatile during the last two decades than it was previously. There are a number of possible reasons for this more settled wage growth position, which include factors such as changes in the labour market and industrial structure and the drivers affecting changes in the behaviour of the unemployed and the economically inactive.

For example, industrial structure has seen a continuing switch from manufacturing to services. Service sector jobs may be generally more flexible (in terms of hiring and firing); similarly, they are often seen as being less unionised. Both of these factors may reduce wage pressures within the labour market.

On a more technical note, studies have shown that the non-accelerating inflation rate of unemployment (NAIRU), that is, the rate of unemployment consistent with sustainable or trend output growth, may have changed. Put simply, it is the rate of unemployment below which inflation will start to accelerate. During the early 1980s, the UK NAIRU was widely perceived as being around 7 per cent. However, unemployment has consistently been below this figure since 1997 without signs of significant inflationary pressure. For these reasons, the NAIRU would appear to have fallen. This could be a result of the factors above and the labour market reforms of the 1980s and 1990s increasing labour market flexibility. ${ }^{4}$

Any assessment of wage pressures also needs to take account of the effect of the economically inactive on total labour supply, because a significant proportion of people entering employment do so directly from inactivity, and are never classified as unemployed. An increase in the potential labour supply, resulting from either growth in the number of inactive through demographic changes or an increase in the numbers among them who are most likely to seek work, can reduce pressures within the labour market. However, the inactivity rate has not changed much over the last 30 years. The rate peaked at 22.8 per cent in the early 1980s, before dipping to 19.4 per cent later that decade, but during the 1990s and more recently it was between 21 to 22 per cent.

Another factor affecting wage pressures may have been an impact from the monetary policy framework introduced in recent years, initially with the move to direct inflation targeting in the early 1990s and then the introduction of the independent Monetary Policy Committee in 1997. If these measures have affected individuals' expectations of inflation, they may have in turn affected wage claims. Greater credibility for policy should lead individuals to expect lower, more stable, inflation, thereby tending to encourage lower pay settlements in line with those expectations.

\section{Labour market coherence with economic performance}

Since 2007, commentators on the

UK economy have been forecasting a slowdown in economic growth and even the recession. ${ }^{5}$ However, what is actually meant by recession can differ according to the commentator. This is because although two quarters of negative economic growth is certainly a good sign of a weakened economy, it is possible for unemployment to rise, or GDP per capita to fall without negative GDP growth. Because of this, it is important to understand the direction of commodity prices and imports (as the pressures on domestic production), the long-term potential output and actual output for an economy, financial markets and inflation. Early indicators of pressures on the UK economy, and hence the labour market, included the decline in the financial markets (see FTSE100 in the past two years) and the increase in commodity prices since 2005.

Labour market indicators were not as quick to falter. Nonetheless, the impact of the decline in GDP is now manifesting itself in labour statistics. The fact that the labour market has lagged behind other indicators is because of economic reasons. The most important of these is that firing employees is not always the most efficient or rational decision for firms because of the fixed costs associated with hiring.

In addition, the financial and business services sector is now one of the most important sectors in the economy. This increased role in the UK economy has meant that different economic influences have become more important to the labour market position than when manufacturing was the main economic driver. One of the main factors influencing the expectations of a slowdown or recession has been the now infamous 'credit crisis' (see Box 1). Although the sub-prime market had been identified as a threat to US economic growth in 2007, it took financial institutions across the world over a year to fully appreciate the consequences of

\section{Box 1}

\section{The impact of the credit crisis on the labour market}

The credit crisis has severely limited the ability of individuals and companies to borrow (gain credit), either to purchase goods or invest, both in the UK and globally. The problem is rooted in the way in which bad risks (debt) were packaged together by commercial and investment banks and sold on to each other. The most significant, and easily understood, bad risk was the sub-prime market that emerged in the US during 2007. The sub-prime market was typified by high-risk lending to mortgage customers who became unable to pay their instalments. However, the banks were able to carry out these innovative operations because of the ease in which debts could be spread across international financial markets, and insufficient regulation to prevent overly risky practices.
During 2008, as more banks feared they were exposed to bad debts, trust in them, of each other, and by the public, eroded. The distrust between banks was extremely costly for the economy because lending effectively ground to a halt; uncertainty therefore increased and confidence reduced in the potential of the economy. As a result of this, the labour market had to suffer at some point. As the availability of credit impacted on consumers, they were forced to revise their demand for goods and services. At the same time, companies could no longer invest in expanding output, or did not have sufficient liquidity to cover costs and therefore needed to reduce output. With less demand in the economy, there was inevitably a reduced need for labour. 
their exposure to its collapse. In the UK, the culmination was the near collapse of Northern Rock, in early 2008, and subsequent injections of liquidity into markets by the Government and Bank of England. In the UK financial sector, the most aggressive labour market restructuring began following the fate of international banking brands in September 2008 (for example, the bankruptcy of Lehman Brothers and takeover of Merrill Lynch).

\section{The economic background to 2008}

The economic position of the UK in 2008 was perhaps more obviously linked to the global economic picture than in recent years. This has been highlighted by the path of world commodity prices ${ }^{6}$ since 2005 , the unravelling of the financial crisis and the realisation that commercial banks in major economies are heavily interdependent.

In the first three quarters of 2008, and the three preceding calendar years, the UK's major international trading partners were the US, Germany, France and China, as measured by trade in goods. These relationships are important for the domestic labour market because UK exports require UK labour inputs, and imports to the UK mean that UK labour is not needed as an input.

Figure 1 shows that, between 2000 and 2003, economic growth was more volatile in France, Germany and the US than in the UK, even recording negative figures. Between 2003 and 2006, the UK, France and the US economies were similar, fluctuating around 0.5 per cent growth. GDP in Germany during this period remained unstable, but moved upwards to a peak of 1.5 per cent in 2006. In 2007, the quarterly growth figures showed weakening economic prospects for three of the four economic areas: the US recorded a second quarter of zero growth within the calendar year, and France and the UK began to consistently record reduced growth figures. Germany dropped below 0.5 per cent growth in the first quarter of 2007, before recording 1.4 per cent growth in the first quarter of 2008. However, this spike in growth quickly turned into a contraction in the economy in the second quarter.

The deteriorating economic growth culminated in the first negative output growth for some time in all four economies (since 1992 in the UK, since 2001 in the US, since 2002 in France and since 2004 in Germany). It can be seen in Figure 1 that the timing of the negative growth differed slightly. In 2008, the US recorded two periods of weak positive growth, before reporting negative growth in the third quarter. The negative growth occurred in the second quarter of 2008 in France and Germany; however, the latest quarter growth figures shows that the German economy has contracted again, while the French economy has not. Finally, UK output reduced in successive quarters from the second quarter of 2007, and it recorded negative growth in the third quarter of 2008. The third quarter figures for the UK and US confirmed that their economies had moved from a slowdown in output to a contraction of the economy.

In terms of employment rates, the impact of the downturn of the economy on the labour market in the UK remained unclear throughout 2007, as output moved towards negative growth. In fact, the employment rate of the population below state pension age increased in 2007, from 74.4 per cent in the three months to March to 74.8 per cent in the three months to December. In 2008, the employment rate began to reflect the slowdown in the output indicators, as it fell almost continuously to reach 74.2 per cent in the three months to September.

Looking at both the unemployment and employment rates, a more coherent picture emerges. The slowdown in economic output can be traced on the unemployment series shown in Figure 2. The UK unemployment rate first began to rise in during 2005, before levelling off in 2006. The small fall in the unemployment rate in 2007 was replaced by five successive increases in 2008. In September 2008, the unemployment rate was 6.0 per cent, which it had not reached since 1999. In the US, unemployment increased from a low of 4.4 per cent in March 2007 to 6.7 per cent in November 2008. In contrast, the employment rate for those aged 16 and over remained close to the rate of the past four years of 66 per cent for most of 2007 and 2008. However, both November and December 2008 were below 66 per cent. Similarly, the labour market performance of the EU15 (which does include the UK) did not appear to deteriorate, when only the employment rate is considered. However, the increase in the unemployment rate throughout 2008 presents a similar picture to that of the UK and the US.

Indicators of the slowdown can also be seen in other ONS statistics. For example, there have been signs that growth in consumer demand has responded to the weak economic outlook. Quarterly growth in UK household final consumption expenditure recorded the first successive negative growth figures, in the second and third quarters of 2008, since the last officially recognised recession in 1991. Meanwhile, in the third quarter, the UK recorded zero per cent retail sales growth. Although there have been periods of weak

\section{Figure 1 \\ GDP growth}

Percentage change, quarter on quarter

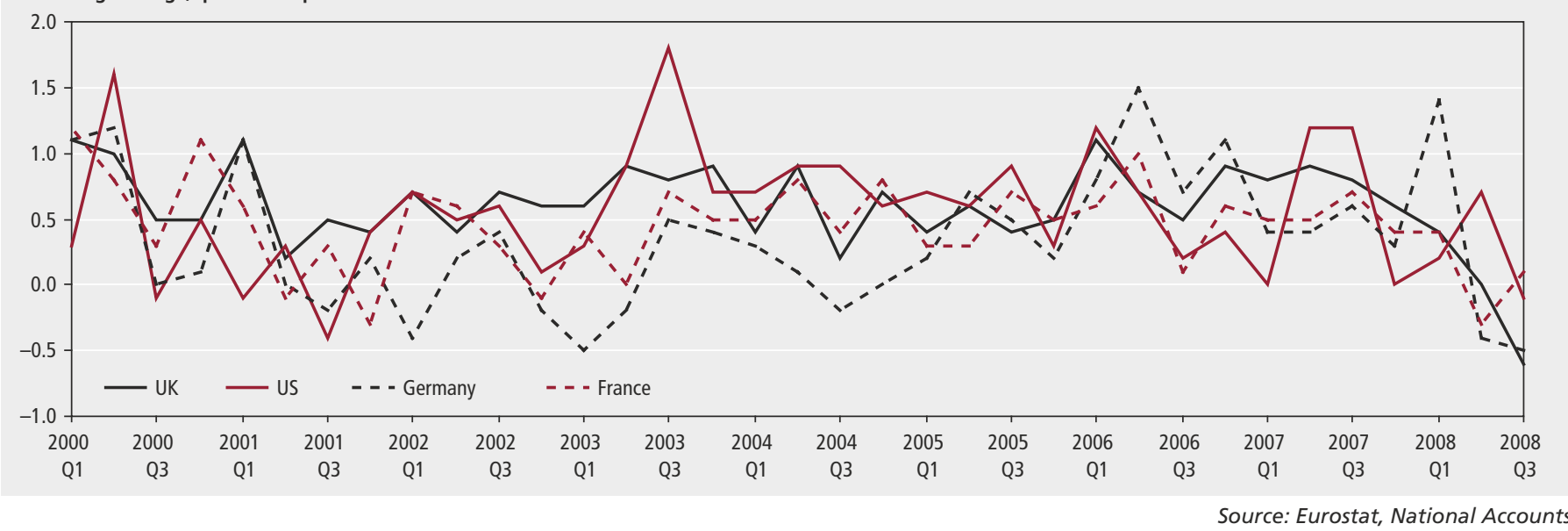


Figure 2

\section{Monthly unemployment rates}

Percentages, seasonally adjusted

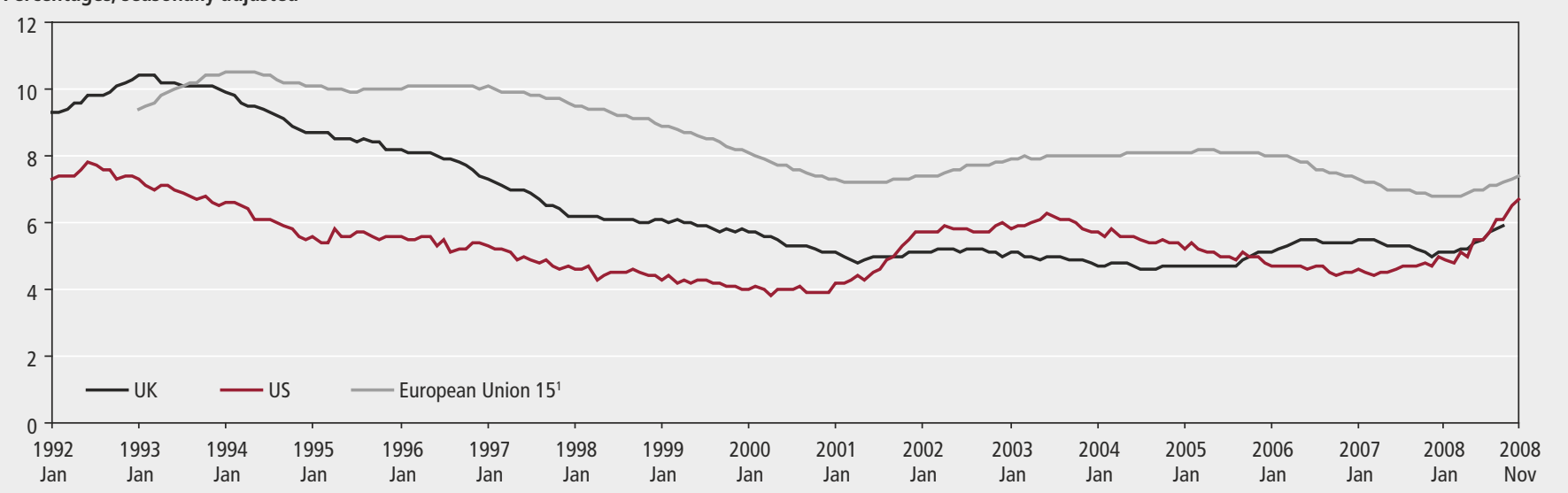

Notes:

Source: Eurostat

1 European Union 15 data are only available from 1993 and include the UK. The EU15 consists of Belgium, France, Germany, Italy, Luxembourg, Netherlands, Ireland, Denmark, Portugal, Greece, Spain, Austria, Finland, Sweden and the UK.

growth since the first quarter of 2006 (the last negative growth period), the quarteron-quarter growth in sales has been predominantly above 1 per cent and close to 2 per cent.

Another sign of reduced labour demand is a reduction in real earnings (although this does assume that inflation is not falling as well). In the late 1990s, quarterly economic growth exceeded 0.5 per cent, as shown in Figure 1. At the same time as real earnings were increasing, both average earnings including and excluding bonuses were predominantly increasing, by 2 percentage points more than inflation (as measured by the Retail Prices Index (RPI)). A similar differential between the series existed between 2000 and 2005. However, since 2006, both average earnings indices have been much closer to the RPI, and in 2008 the RPI was higher than average earnings in the second and third quarters.

\section{Other economic factors in 2008}

Alongside the economic factors already mentioned in 2008, there were a number of specific events or factors that had an impact on the labour market during the year.

The most obvious was the development of global commodity prices throughout the year. Although some of the prices have now eased off, the scale of the increase led to people drawing comparisons with the 1970s. The International Monetary Fund reported that oil prices more than doubled between December 2006 and mid-July 2008, and over a similar time period metal prices also increased drastically. As a developed economy reliant on oil and metals for either consumption or production, this inevitably had repercussions for aggregate demand in the UK.

Inevitably, the large increases in global commodity prices fed through to the domestic UK economy, and subsequently introduced inflationary pressures in 2007 and early 2008. The consequence of this was that the Bank of England had to be even more mindful of inflationary pressures when setting interest rates at a time when the threats to economic growth were increasing.

Government policy developments will also have impacted on the labour market. In 2008, the DWP announced proposals to influence the labour supply through incapacity benefits and loneparent payments among other policy initiatives. HM Treasury and HM Revenue \& Customs made changes to the tax system in the 2008 Budget, including abolishing the 10 per cent tax rate introduced in the previous Budget. However, it is likely that the most important government interventions for 2008 and the future related to monetary, fiscal and financial policy designed to influence the wider economy. In September 2008, this involved providing $£ 200$ billion to the Bank of England’s special liquidity scheme and $£ 50$ billion to a bank recapitalisation fund. In addition to this, HM Treasury announced that public investment from 2010/11 would be brought forward to 2008/09 and 2009/10, and a temporary VAT reduction (to 15 per cent) would be in place between December 2008 and 2009.

\section{Notes}

1 Participation rates by gender are provided in the Labour Market First Release at www.statistics.gov.uk/statbase/product. asp?vlnk $=1944$

2 Estimates of the UK population can be found at www.statistics.gov.uk/cci/nugget. asp?id=6

and at www.statistics.gov.uk/pdfdir/ popest0808.pdf

3 The National Insurance number applications are published by the Department for Work and Pensions at www.dwp.gov.uk/asd/tabtool.asp\#ni_ alloc

4 An article discussing the nonaccelerating inflation rate of unemployment can be found at www.bankofengland.co.uk/ publications/externalmpcpapers/ extmpcpaper0012.pdf

5 A discussion of how a recession is measured can be found on The Economist website at www.economist.com/finance/ displaystory.cfm?story_id=12207987

6 A discussion on world commodity prices can be found on the International Monetary Fund (IMF) website at www.imf.org/external/pubs/ft/ weo/2008/02/pdf/c3.pdf

7 The Pre-Budget and Budget report for 2007 and 2008 can be found on the HM Treasury website at www.hm-treasury.gov.uk/prebud_ pbr08_index.htm

\section{CONTACT}

elmr@ons.gsi.gov.uk 